\title{
Bipolar Precharger for Hybrid Electrostatic Filtration Systems
}

Aerosol and Air Quality Research

\section{OPEN ACCESS}

Received: August 31, 2021

Revised: November 21, 2021

Accepted: November 24, 2021

\author{
${ }^{*}$ Corresponding Authors: \\ Yufeng Chang \\ cyf15107@jhun.edu.cn \\ Pei Jia \\ ddjp1980@wit.edu.cn
}

\section{Publisher:}

Taiwan Association for Aerosol Research

ISSN: $1680-8584$ print

ISSN: 2071-1409 online

\section{Copyright: The Author(s).} This is an open access article distributed under the terms of the Creative Commons Attribution License (CC BY 4.0), which permits unrestricted use, distribution, and reproduction in any medium, provided the original author and source are cited.

\author{
Yufeng Chang ${ }^{1^{*}}$, Ling Shi ${ }^{1}$, Pei Jia ${ }^{2^{*}}$ \\ ${ }^{1}$ Hubei Key Laboratory of Industrial Fume and Dust Pollution Control, Jianghan University, \\ Wuhan 430056, China \\ ${ }^{2}$ School of Resources and Safety Engineering, Wuhan Institute of Technology, Wuhan 430073, \\ China
}

\section{ABSTRACT}

Both hybrid electrostatic filtration and agglomeration technologies can effectively improve the efficiency of fine particle collection. A hybrid electrostatic filtration system with a wire-tube bipolar precharger was developed on the basis of bipolar transverse plate electrostatic precipitation technology. Theoretical analyses of electric field and flow field distribution showed that a uniform electric field and high turbulence intensity improve ion migration and particle agglomeration in the novel wire-tube bipolar precharger. The influence of unipolar and bipolar prechargers on dust removal was investigated. In the hybrid electrostatic filtration system with the bipolar precharger, the corona current was $30 \%$ higher, the particles deposited on the surface of the filter bag were $19 \%$ larger, and the pressure drop was $30 \%$ smaller than a filtration system with a unipolar precharger. When silicon powder with a median diameter of $1.7 \mu \mathrm{m}$ was used, the mean penetration of the experimental device with the bipolar precharger was $45 \%$ lower than that of the experimental device with the unipolar precharger.

Keywords: Bipolar agglomeration, Fine particle, Electric field, Collection efficiency

\section{INTRODUCTION}

Hybrid electrostatic filtration systems are used in competitive approaches for achieving efficient control of fine particle emissions to meet stringent emission standards (Chang et al., 2019; Jaworek et al., 2019; Ni et al., 2018; Robert and Nallathambi, 2020). Typical examples of hybrid electrostatic precipitators built at the industrial scale are the compact hybrid particulate collector and advanced hybrid particulate collector (Chang, 1992; Miller, 1999). Higher collection efficiency, higher face velocity, and lower pressure drops have been achieved by these hybrid electrostatic precipitators (Feng et al., 2016; Wang et al., 2016; Tu et al., 2018; Xiang et al., 2018).

Another method of reducing fine particle emissions is to increase the particles' size in an agglomerator before precipitation (Jaworek et al., 2007). Many agglomeration technologies have been proposed to promote the growth of fine particles. Acoustic coagulation, water vapor condensation, chemical agglomeration, and electrostatic agglomeration are the most frequently proposed methods (Deng et al., 2010; Hu et al., 2018; Liu and Li, 2020; Thonglek and Kiatsiriroat, 2014). Among these methods, electrostatic agglomeration has the highest energy efficiency. However, because of the complexity of their structure, electrostatic agglomerators have rarely been employed in hybrid electrostatic filtration systems.

In this study, a wire-tube bipolar precharger with an agglomeration function was designed and fabricated for use in hybrid electrostatic filtration systems to improve their collection efficiency. Electrohydrodynamic (EHD) parameter testing was conducted to determine the effect of electrode parameters on corona discharge characteristics and flow field distribution. The corona current, particle removal characteristics, and agglomeration characteristics of the hybrid electrostatic filtration system with wire-tube bipolar precharger were explored experimentally. 


\section{EXPERIMENTAL}

The experimental platform of the hybrid electrostatic filtration system with the wire-tube precharger is shown in Fig. 1. A centrifugal fan was mounted at the outlet of the channel to control the air flow rate. Aerosol was produced by a dust generator and injected into the channel via its inlet. Particle concentration was measured at the inlet and outlet of the channel by using particle measurement devices. The air flow velocity in the channel was measured with a hot-wire anemometer. Particle charging and agglomeration were performed in the precharger, and particle collection was accomplished in the bag filter.

The precharger is made of a polymethyl methacrylate (PMMA) channel with a rectangular cross section of $120 \times 150 \mathrm{~mm}^{2}$ and a length of $180 \mathrm{~mm}$. The precharger contained no dust hopper, so it can be installed in the tunnel. The outlet of the precharger was placed at the bottom of the bag filter. Tungsten wire and stainless-steel tube electrodes were used. The diameter of the tungsten wire electrode was $0.4 \mathrm{~mm}$, and the diameter of the stainless-steel tube electrode was $10 \mathrm{~mm}$. To reduce the pressure drop, tube electrodes were used in place of traditional plate electrodes.

Both a unipolar precharger and bipolar precharger were tested, the geometries of which are shown in Fig. 2.

In the unipolar precharger, the wire electrodes were placed equidistant from the parallel tube electrodes. The tubes were grounded, and the wires were set at a high voltage. Both the wire-towire distance and tube-to-tube distance were $40 \mathrm{~mm}$, and the spacing between the wire and tube electrodes was $20 \mathrm{~mm}$. The electric field area was $116 \times 140 \mathrm{~mm}^{2}$. Eight corona wires and 12 grounded tubes were used.

In the bipolar precharger, each parallel electrodes configuration consisted of one wire and two tubes electrodes, and both the wire-to-tube distance and tube-to-tube distance were $40 \mathrm{~mm}$. The negative electrodes were set at a high voltage, and adjacent electrodes were grounded. The negative electrodes were placed equidistant from the grounded electrodes. The distance between the negative electrode and the grounded electrode was $20 \mathrm{~mm}$. Eight corona wires (four negative wires and four grounded wires) and 16 tubes (eight negative tubes and eight grounded tubes) were placed in the same electric field area. Thus, the bipolar precharger contained four more tubes than the unipolar precharger.

The bag filter consisted of a PMMA channel with a square cross section of $450 \times 450 \mathrm{~mm}^{2}$. A dust hopper was located at the bottom of the bag filter. Filtration was conducted in four cylindrical acetate fiber bags, which were $130 \mathrm{~mm}$ in diameter and $1000 \mathrm{~mm}$ in length and had a total filter surface area of $1.68 \mathrm{~m}^{2}$. For optimization of surface area and ease of bag cleaning, the bags were configured to have the dust gas flow from the outside of the bag to the inside.

Pulse-jet dust-cleaning system

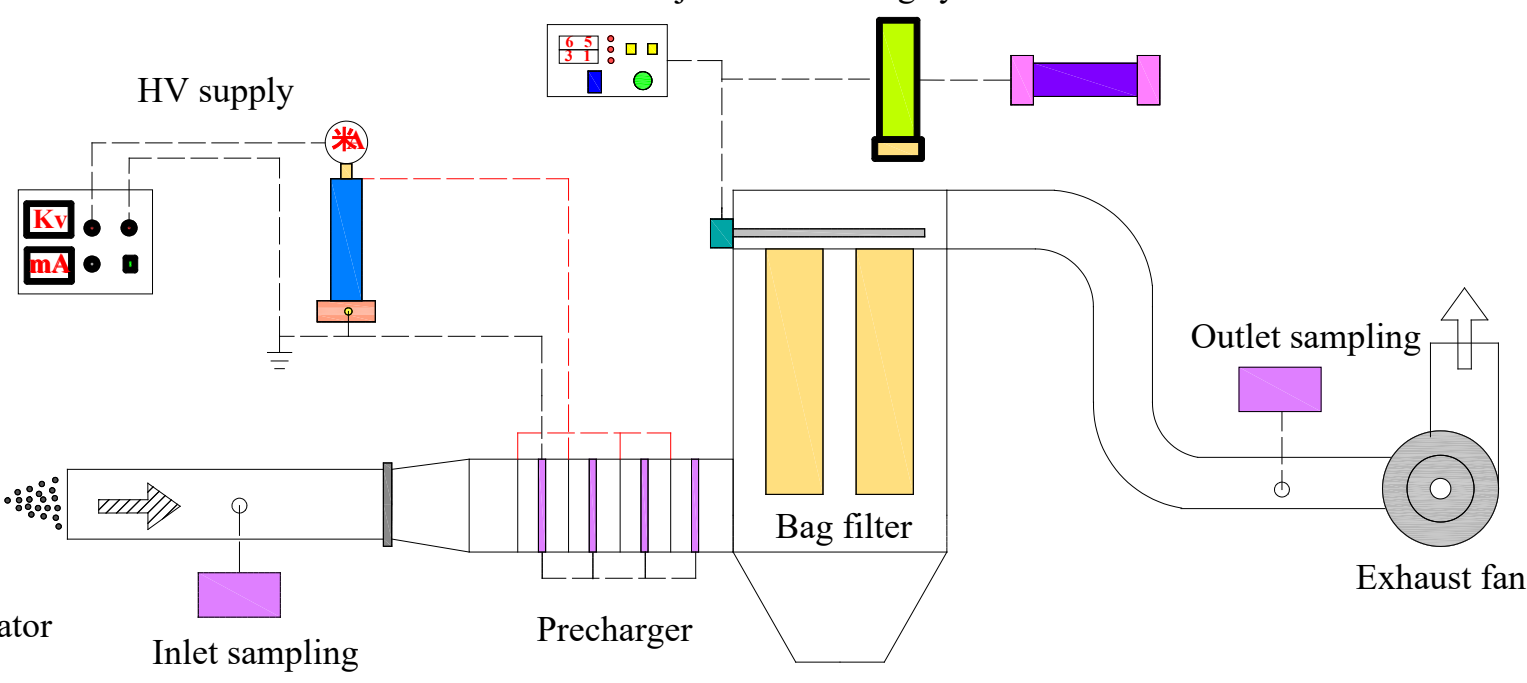

Aerosol generator

Inlet sampling

Fig. 1. Schematic of experimental setup. 
(a)

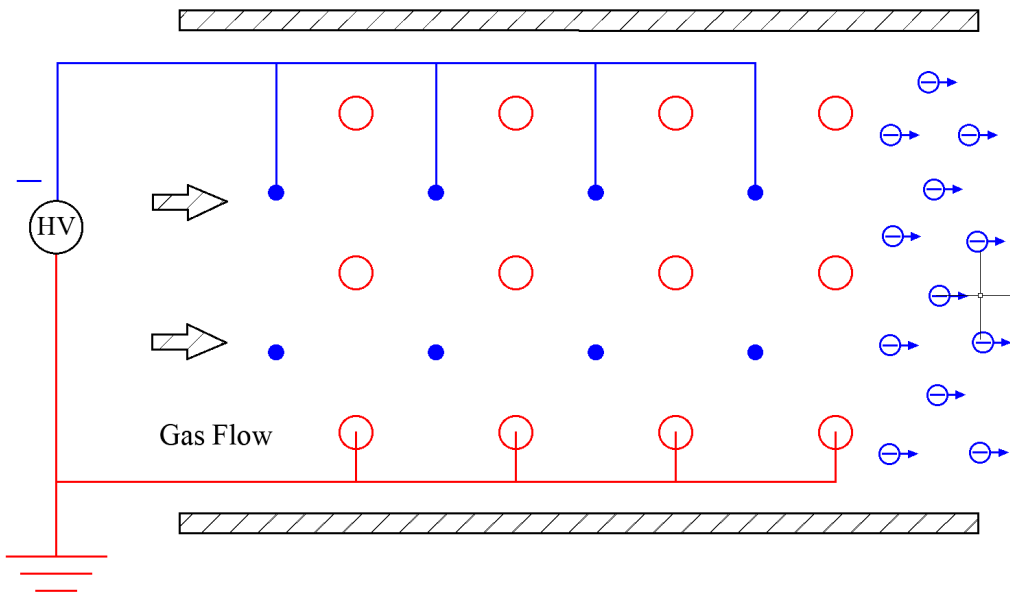

(b)

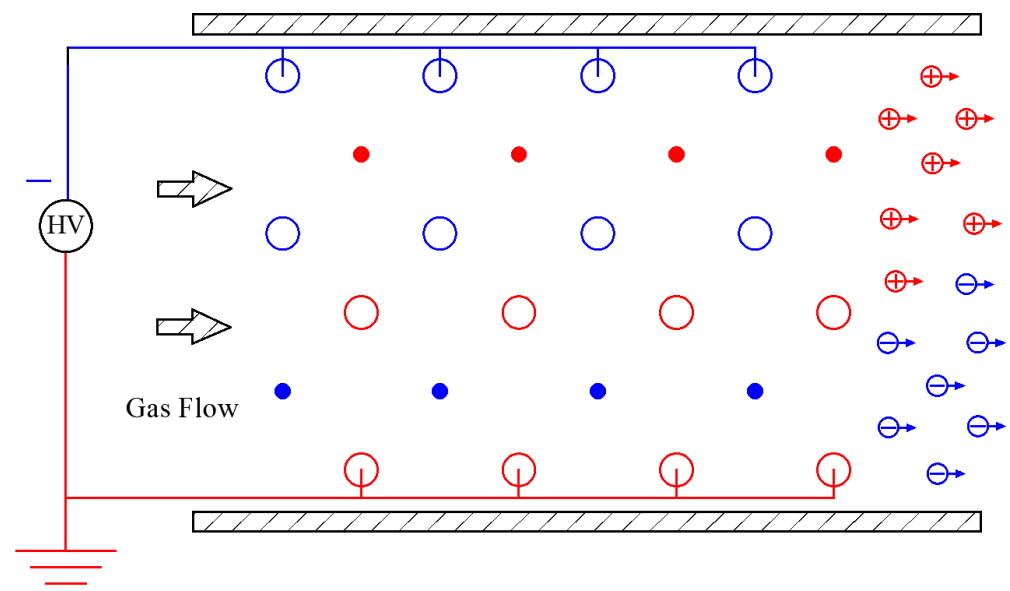

Fig. 2 Geometries of (a) unipolar precharger and (b) bipolar precharger.

\section{SIMULATION AND DISCUSSION}

\subsection{Governing Equations for EHD Flow}

The following equations describe EHD flow in electrostatic precipitation, which is caused by electrostatic forces and aerodynamics.

The electric potential $V$ is governed by Poisson's equation

$\nabla^{2} V=-q / \varepsilon_{0}$

where $q$ is the space charge density $\left(\mathrm{C} \mathrm{m}^{-3}\right)$ and $\varepsilon_{0}$ is the dielectric permittivity of free space $\left(\mathrm{F} \mathrm{m}^{-1}\right)$.

The electric potential can also be defined as

$E=-\nabla V$

where $E$ is the electric field intensity $\left(\mathrm{V} \mathrm{m}^{-1}\right)$.

The electric current in the drifting zone is a combination of conduction, convection, and diffusion. The current density $J$ is given by

$J=k E q+u q-D \nabla q$

where $k$ is the mobility of air ions in an electric field $\left(\mathrm{m} \mathrm{s}^{-1}\right), u$ is the velocity vector of gas flow $\left(\mathrm{m} \mathrm{s}^{-1}\right)$, and $D$ is the diffusivity coefficient of the ions $\left(\mathrm{m}^{2} \mathrm{~s}^{-1}\right)$. The current continuity condition gives the equation for current density: 
$\nabla J=0$

The fluid dynamics part of the problem is described by the Navier-Stokes equation

$\rho u \nabla u=-\nabla p+\mu \nabla^{2} u+F_{E H D}$

and the continuity equation for steady-tate incompressible air flow

$\nabla u=0$

where $\rho$ is the gas density $\left(\mathrm{kg} \mathrm{m}^{-3}\right), p$ is the pressure (Pa), $\mu$ is the dynamic viscosity $\left(\mathrm{kg} \mathrm{m}^{-1} \mathrm{~s}^{-1}\right)$, and $F_{\mathrm{EHD}}$ is the EHD force $\left(\mathrm{N} \mathrm{m}^{-3}\right)$, which is defined as

$F_{E H D}=q_{E}$

\subsection{Simulation and Discussion}

The geometries shown in Fig. 2 were used for numerical simulation models. A single domain was used for the entire simulation space, which consisted of the inside of the rectangular channel with an area of $116 \times 146 \mathrm{~mm}^{2}$. Numerical simulation revealed the electric field distribution, charge distribution, and gas velocity distribution of the unipolar precharger and bipolar prechargers. The plots are shown in Figs. 3 and 4 for the unipolar and bipolar prechargers, respectively, where the electric potential is $-12 \mathrm{kV}$ and the gas velocity is $4.94 \mathrm{~m} \mathrm{~s}^{-1}$.

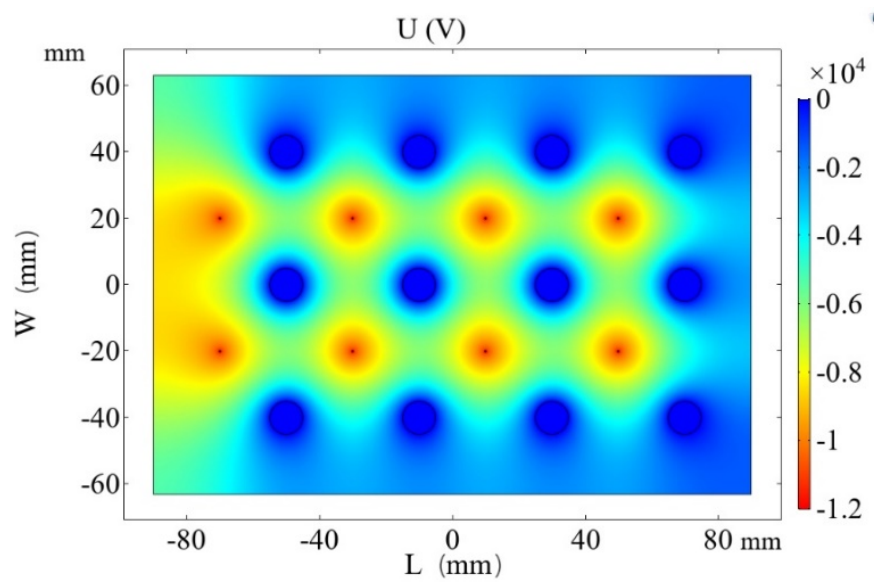

(a)

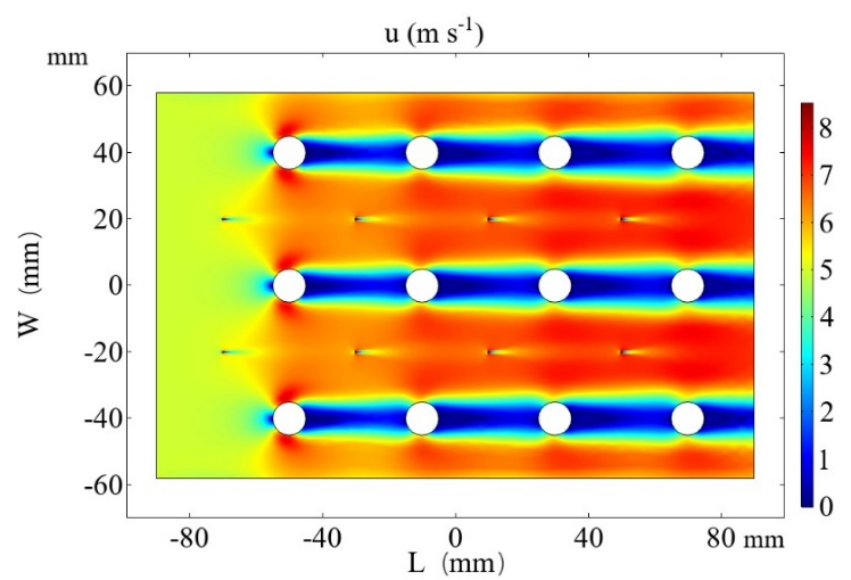

(c)

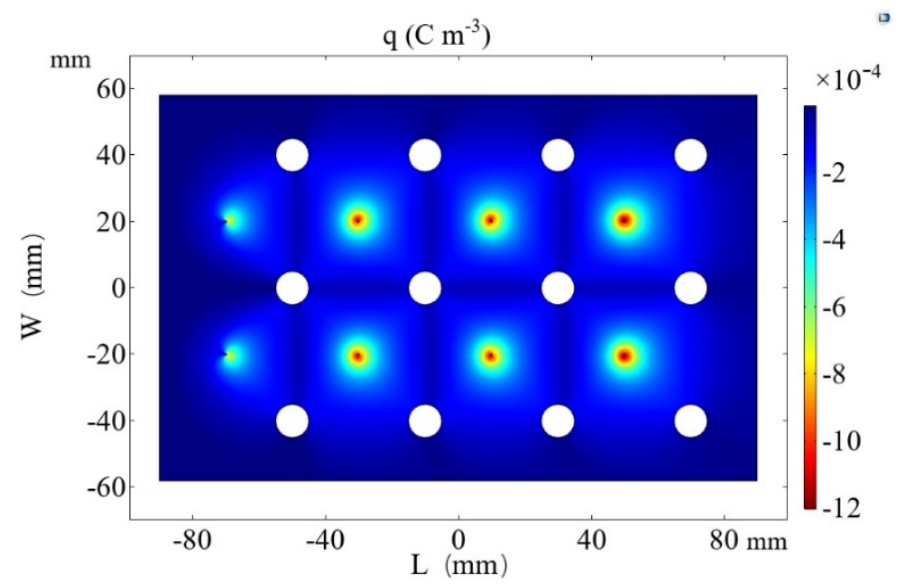

(b)

Fig. 3. Numerical simulation results as surface maps for unipolar precharger: (a) electric potential, (b) space charge density, and (c) gas velocity. 


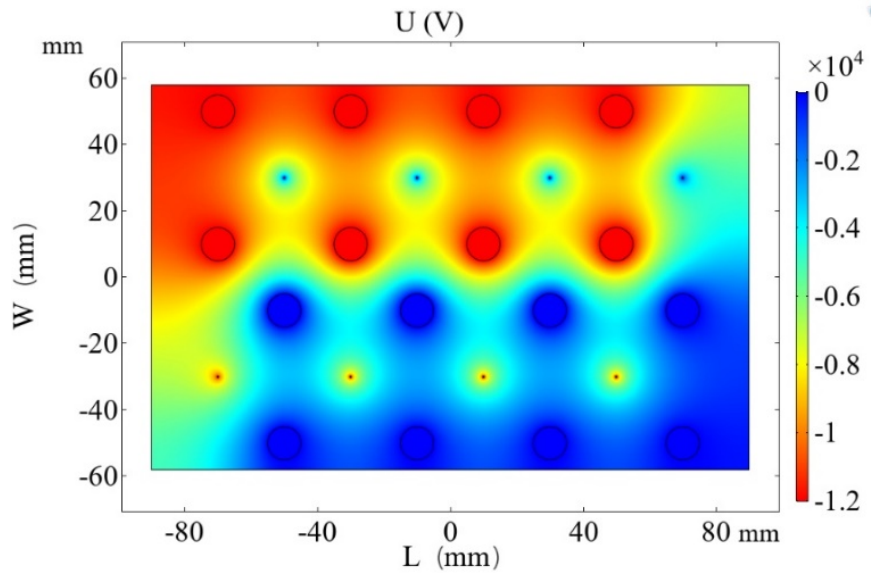

(a)

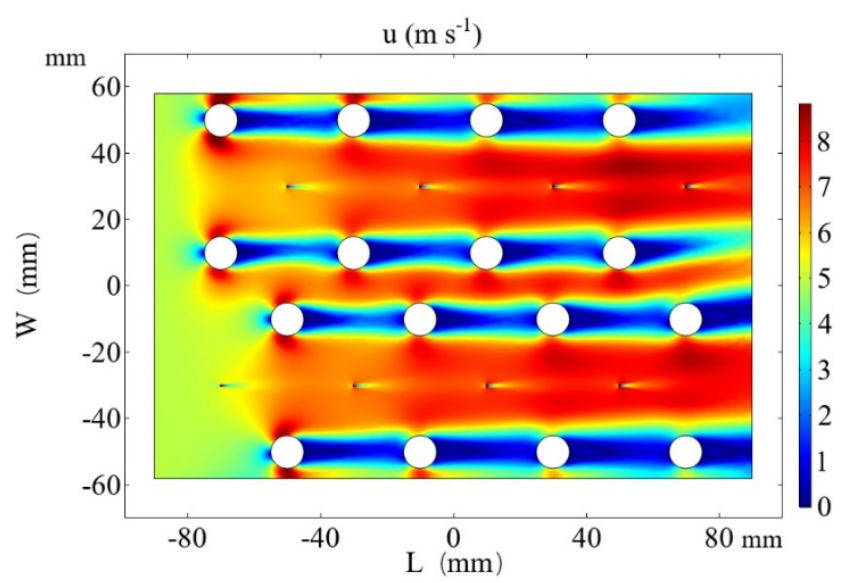

(c)

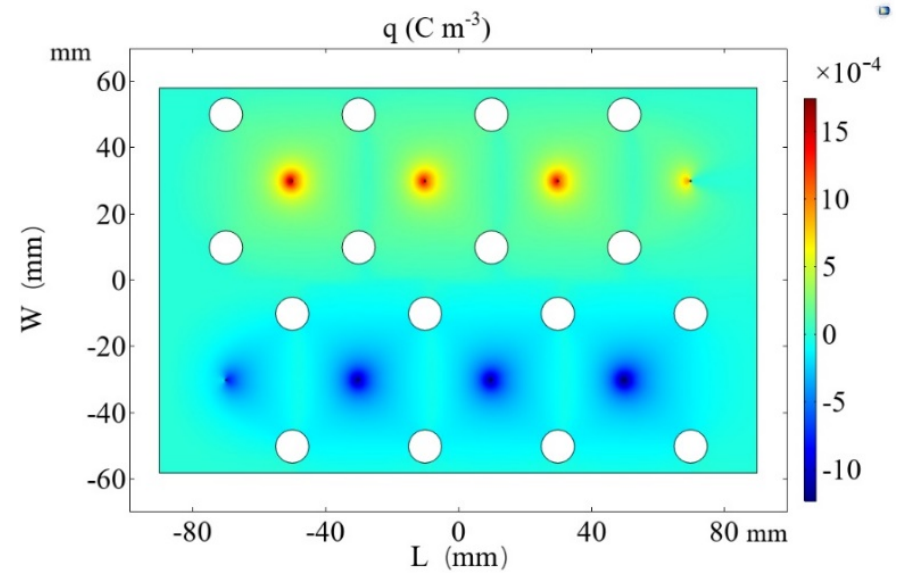

(b)

Fig. 4. Numerical simulation results as surface maps for bipolar precharger: (a) electric potential, (b) space charge density, and (c) gas velocity.

In Fig. 3, the electric potential map shows the greatest magnitude of negative electric potential at the surface of the corona electrode, with the magnitude decreasing from the edge of the corona electrode to the channel walls and grounded tube. Space charge density is highest near the corona electrode and decreases in all directions, with lower charge density near the inlet than at the outlet. The gas velocity along the airflow direction is more than $6 \mathrm{~m} \mathrm{~s}^{-1}$ in the area between wires, and less than $2 \mathrm{~m} \mathrm{~s}^{-1}$ in the area between tubes. These results illustrate that high gas velocity can accelerate the diffusion of corona ions from the corona zone. In the unipolar precharger, only negative corona discharge occurs. Consequently, turbulent agglomeration, rather than electrostatic agglomeration, can occur in the unipolar precharger.

As illustrated in Fig. 4, electric potential increases from the negative electrodes to the grounded electrodes. The magnitude of the negative electric potential in the area between the negative tube electrodes and the channel walls is the greatest. The gas velocity in the airflow direction is more than $7 \mathrm{~m} \mathrm{~s}^{-1}$ in the area between wires and less than $1.5 \mathrm{~m} \mathrm{~s}^{-1}$ in the area between tubes. Higher gas velocity around the wire electrodes can be useful for corona ions escaping from the wires to the gas flow, and larger velocity gradient between wire electrodes and tube electrodes favors turbulence agglomeration.

The greatest magnitude of negative space charge density is near the negative wire electrodes, and the highest positive density is near the grounded wire electrodes. Space charge density decreases in all directions from the wire electrodes. High negative and positive space charge density occurs simultaneously in the bipolar precharger, which can be diffuse to the entire space under the action of turbulence. Consequently, both turbulent agglomeration and electrostatic agglomeration were occurred in the bipolar precharger. 


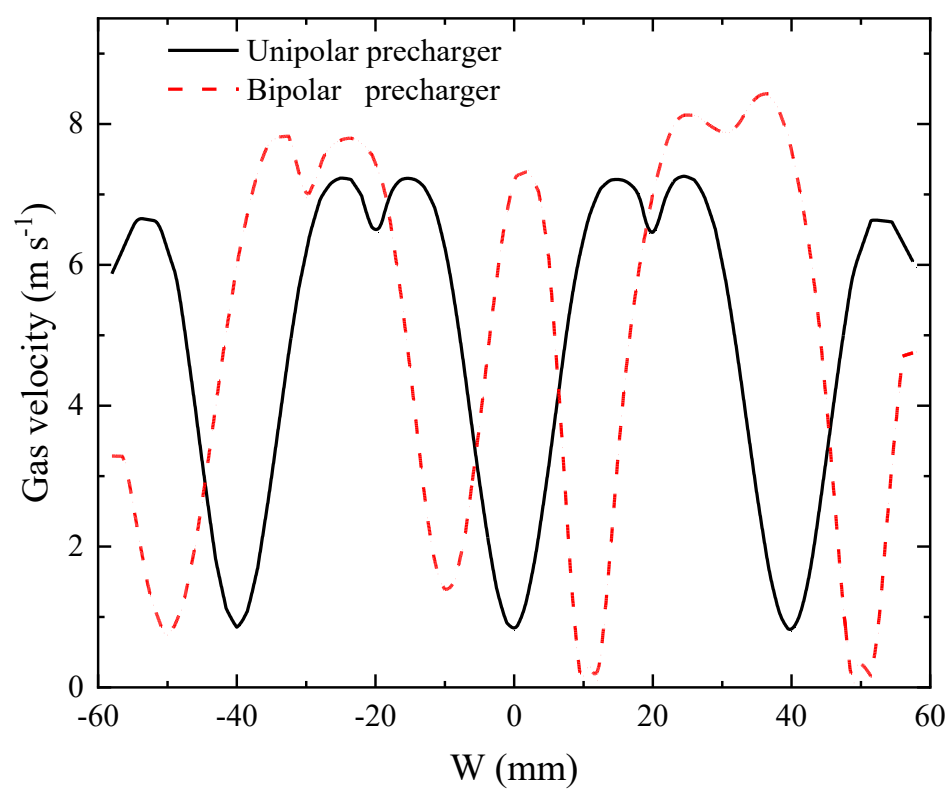

Fig. 5. Comparison of gas velocity in unipolar and bipolar prechargers.

The coupled gas velocity profile of the middle section between the negative electrodes and the grounded electrodes is shown in Fig. 5.

Strong turbulent motion occurs in both prechargers. The turbulence intensity along the $y$-axis in the bipolar precharger is higher than that in the unipolar precharger.

The charging rather than the collection process is emphasized for a precharger; therefore, a higher gas velocity is desirable. To visualize the relationship between electric field parameters and gas flow, the EHD parameters $E_{h d}$ and $R e$ are introduced to evaluate the influence of EHD flow on primary flow (Feng et al., 2018; IEEE-DEIS-EHD Technical Committee, 2003; Krupa et al., 2019); these parameters are defined as

$E_{h d}=\frac{\rho l L^{3}}{\mu^{2} k A}$

$R_{e}=\frac{\rho u L}{\mu}$

where $I$ is the current density $(A), L$ is the characteristic length $(\mathrm{m})$, and $A$ is the surface area of the collection electrodes $\left(\mathrm{m}^{2}\right)$. When $E_{h d} \gg R e^{2}$, the EHD induced secondary flow becomes important for primary flow.

Substituting the characteristic parameters into Eqs. (8) and (9) yields

$E_{h d-U}=3.03 \times 10^{8}, E_{h d-B}=3.15 \times 10^{8}, R e=5.93 \times 10^{4}$,

and

$\frac{E_{h d-U}}{R e^{2}} \approx \frac{E_{h d-B}}{R e^{2}}=0.09$

where $E_{h d-U}$ and $E_{h d-B}$ are the EHD parameters for the unipolar precharger and bipolar precharger, respectively.

Because of the higher gas velocity, EHD-induced secondary flow has no significant effect on primary flow in either precharger. The influence of EHD flow on primary flow in the unipolar precharger is $4 \%$ lower than that in the bipolar precharger. This indicates that the turbulence 
intensity in the bipolar precharger is slightly higher than that in the unipolar precharger. This also contributes to greater ion migration velocity and turbulence agglomeration for the bipolar precharger. High face velocity can be useful for agglomeration in the bipolar precharger in industrial applications. The dust removal device can be made smaller to allow for a reduction in investment costs and required construction space.

\section{EXPERIMENTAL RESULTS AND DISCUSSION}

The experiments were carried out in the laboratory condition. The temperature was about 20 to $25^{\circ} \mathrm{C}$, and the relative humidity was $60 \%$ to $80 \%$. The concentration of dried dust at the inlet was about $2500 \mathrm{mg} \mathrm{m}^{-3}$.

\subsection{Voltage-Current Characteristics}

A $60 \mathrm{kV} / 5.0 \mathrm{~mA}$ negative voltage generator was used for voltage supply. The output of the voltage and the current can be read directly from the meters on the voltage generator. The voltage-current $(V-I)$ characteristics of the experimental devices are presented in Fig. 6 .

The results indicate that the inception voltage was approximately $3 \mathrm{kV}$ for the bipolar precharger and approximately $5 \mathrm{kV}$ for the unipolar precharger. The corona current of the bipolar precharger was approximately $30 \%$ higher than that of the unipolar precharger at DC supply voltages between 11 and $13 \mathrm{kV}$. These results were attribute to the 1.33 -fold number of tube electrodes in the same area in the bipolar charger compared with the unipolar precharger. A lower inception voltage and higher corona current result in favorable corona discharge characteristics for the bipolar precharger (Chang et al., 2018).

\subsection{Particle Agglomeration}

To achieve a fine particle size, silicon powder was selected as the experimental dust. The particle diameter distribution of the initial dust in the laboratory was measured with a laser particle size analyzer. Particle size was calculated by measuring the angle of light scattered by the particles as they pass through the laser beam. As shown in Fig. 7, the median particle diameter was $1.73 \mu \mathrm{m}$, and particles with diameters of at least $2.5 \mu \mathrm{m}$ accounted for less than $30 \%$ of the total volume. The experimental dust can well characterize fine particles (He et al., 2018).

The particle diameter distribution of the dust deposited on the surface of the filter bag was measured after the experiment; these results are shown in Fig. 8.

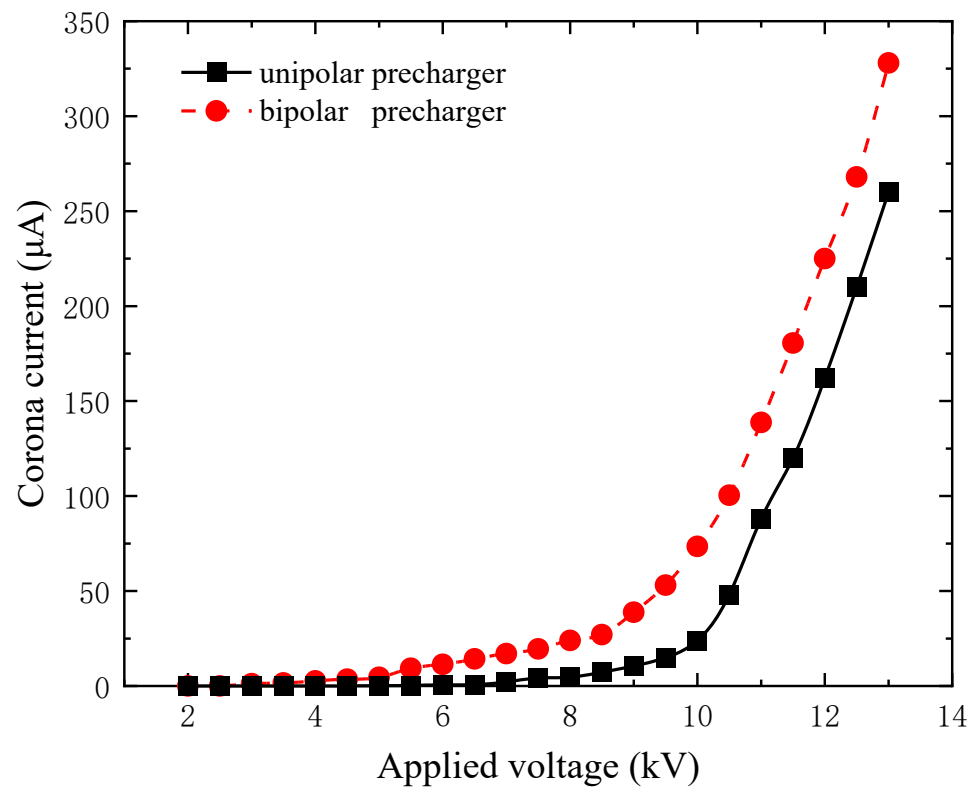

Fig. 6. $V$-I characteristics of experimental devices. 


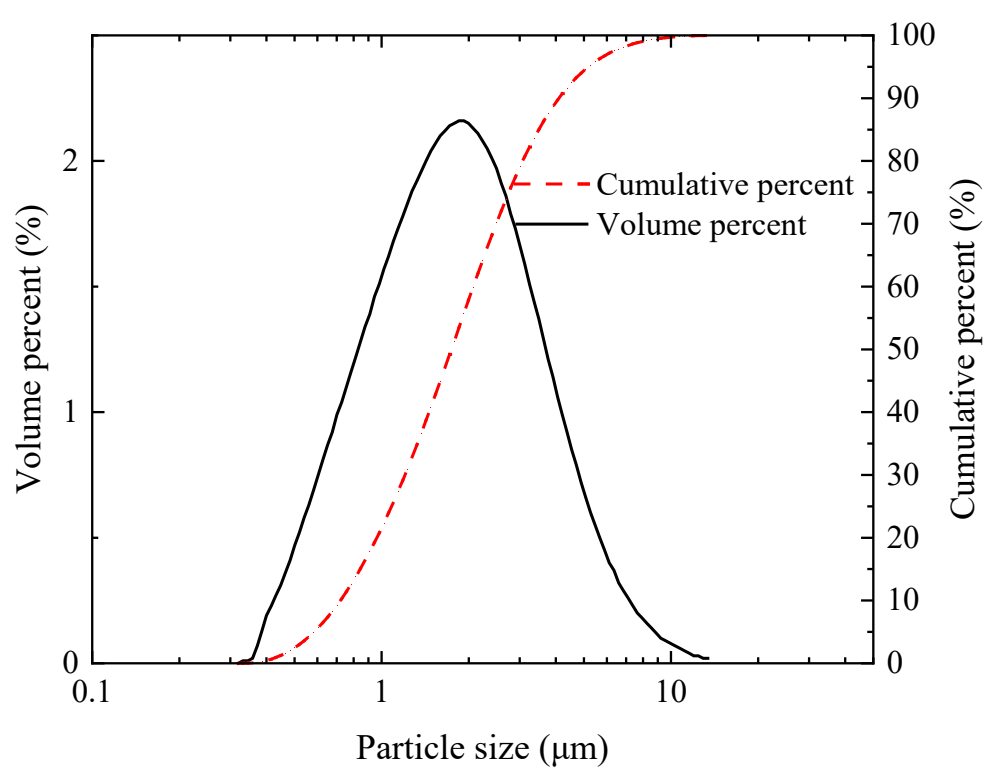

Fig. 7. Particle diameter distribution of test dust.

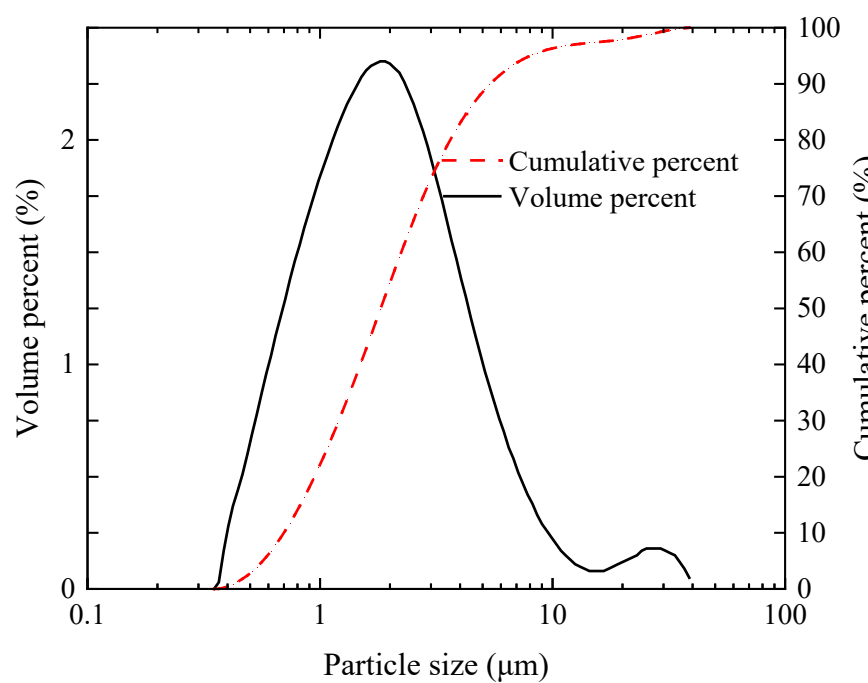

(a)

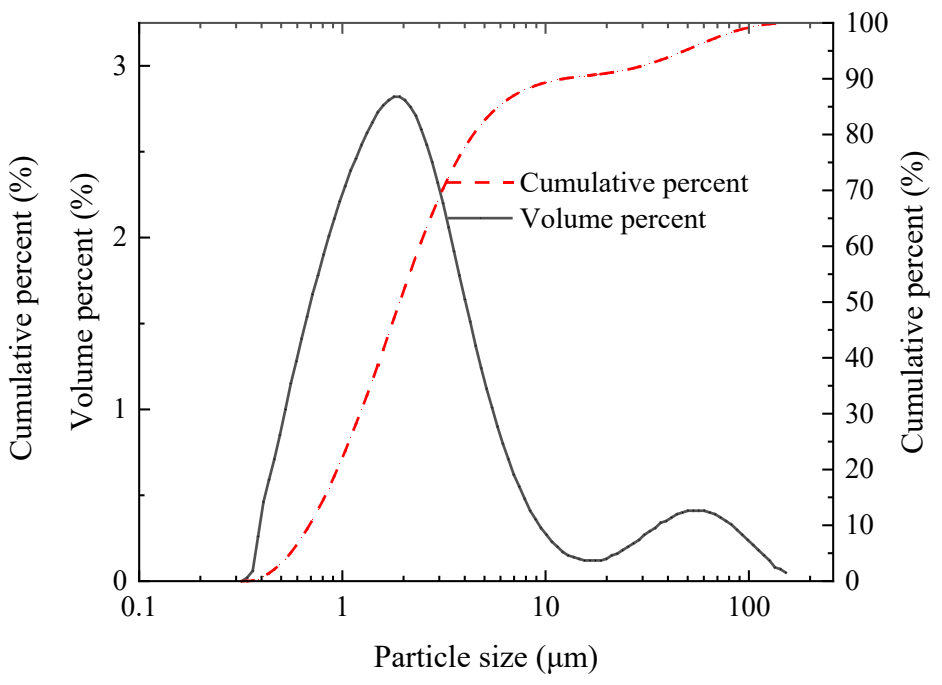

(b)

Fig. 8. Particle diameter distribution on the surface of filter bag for (a) unipolar precharger and (b) bipolar precharger.

The median particle diameter was larger than that of the initial dust in both cases, and the particle diameter distribution was bimodal. The dust on the surface of the bag filter with the unipolar precharger had a median diameter of $1.98 \mu \mathrm{m}$, which was $14 \%$ larger than that of the initial dust, and particles with diameters of at least $2.5 \mu \mathrm{m}$ accounted for less than $40 \%$ of the total volume. The dust on surface of the bag filter with the bipolar precharger had a median diameter of $2.35 \mu \mathrm{m}$, which was $36 \%$ larger than that of the initial dust, and particles with diameters of at least $2.5 \mu \mathrm{m}$ accounted for approximately $45 \%$ of the total volume. The median particle diameter was $19 \%$ larger for the device with the bipolar precharger than for the device with unipolar precharger. These results show that the bipolar precharger can promote agglomeration of charged particles (Chen et al., 2017; Sobczyk et al., 2017).

\subsection{Pressure Drop}

The pressure drops of the experimental devices are shown in Fig. 9.

The results illustrate that the pressure drop of the device with the bipolar precharger was $30 \%$ 


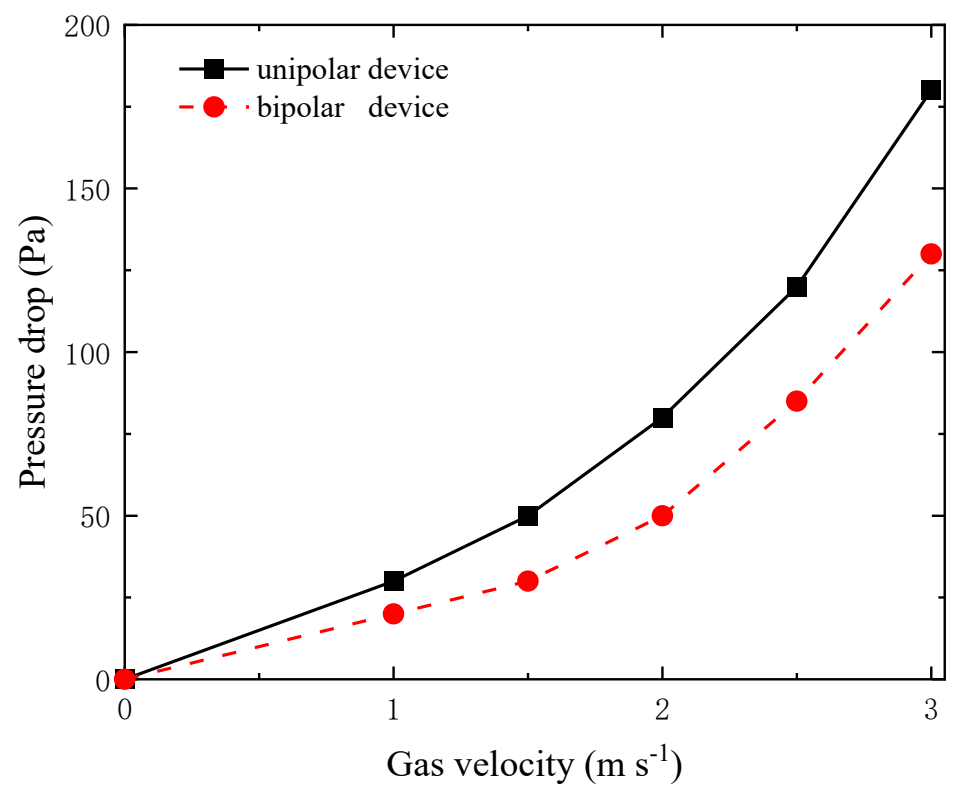

Fig. 9. Pressure drops of experimental devices.

smaller than that of device with the unipolar precharger. Because of electrostatic agglomeration in the device with the bipolar precharger, the charged particles deposited on the surface of the bag filter were larger in diameter and higher in porosity than those in the device with unipolar precharger. The porous structure of the dust cake is conducive to a smaller pressure drop across the filter and allows for longer filter regeneration cycles. Then, the costs of fan, compressed air, bag filters and maintenance were reduced in the system (Noh et al., 2011).

\subsection{Collection Efficiency}

An experiment was conducted in which the DC supply voltage of the collection stage was varied from -9 to $-12 \mathrm{kV}$, the results of which are presented in Fig. 10. The vertical axis corresponds to the collection efficiency at a specific face velocity of $0.05 \mathrm{~m} \mathrm{~s}^{-1}$. The corresponding mean electric field strength in each precharger ranged from 4.5 to $6.0 \mathrm{kV} \mathrm{cm}^{-1}$.

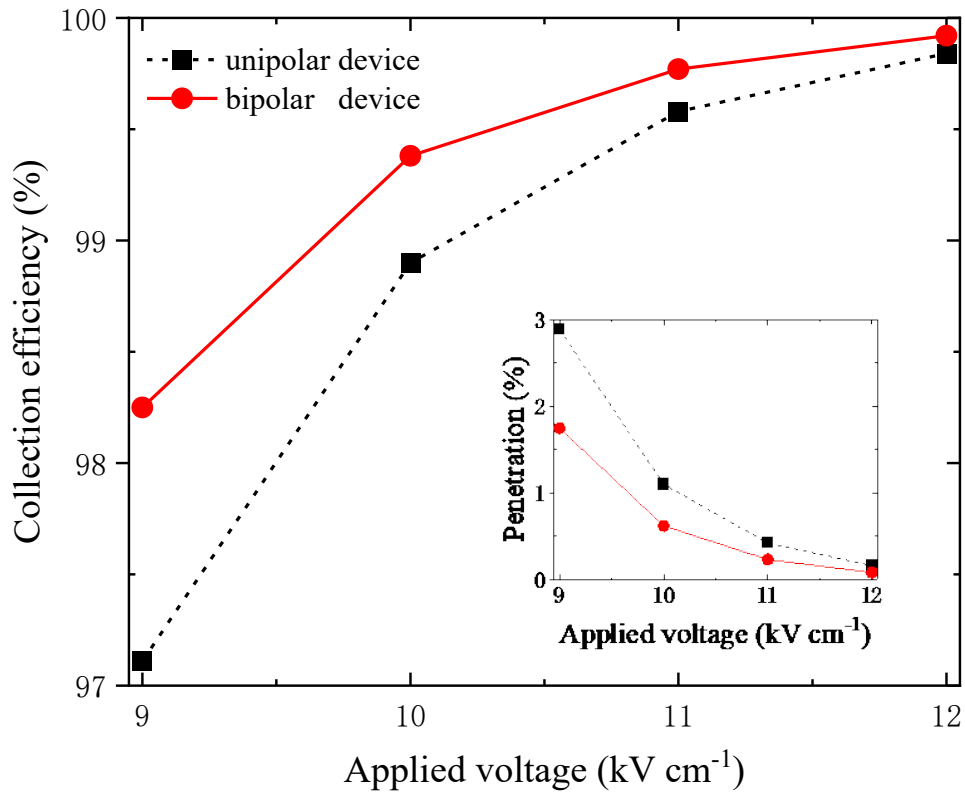

Fig. 10. Collection efficiency of experimental devices. 
As illustrated in Fig. 10, the collection efficiency increased with voltage in both prechargers. The mean penetration of the device with the bipolar precharger was $45 \%$ lower than that of the device with the unipolar precharger under an applied voltage of -9 to $-12 \mathrm{kV}$. The larger the applied voltage is, the lower is the penetration of particles through the filter.

\section{CONCLUSIONS}

In this study, a bipolar wire-tube precharger was designed to enhance particle removal efficiency in electrostatic filtration systems. The bipolar wire-tube precharger considerably improves dust removal efficiency.

1) The configuration of the bipolar precharger's wire-tube electrodes generated negative and positive space charge density simultaneously, which is beneficial for corona discharge and electrostatic agglomeration. The EHD induced secondary flow has no significant effect on primary flow. The EHD parameter of the bipolar precharger is $4 \%$ higher than that of the unipolar precharger.

2) Compared to the unipolar precharger, the corona current was $30 \%$ higher, the particle at the outlet was $19 \%$ larger, pressure drop was $30 \%$ smaller, and the penetration was $45 \%$ lower in the bipolar precharger. So, the bipolar precharger is therefore proposed for coagulating fine particles with higher energy efficiency.

\section{ACKNOWLEDGEMENT}

Financial support from the 2019 Hubei Province Technical Innovation Special Major Project (2019ACA160) were gratefully acknowledged. This manuscript was edited by Wallace Academic Editing.

\section{REFERENCES}

Bruno, J., Rafael, S., Vádila, G., Mônica, L. (2020). Hybrid air filters: A review of the main equipment configurations and results. Process Saf. Environ. Prot. 144, 193-207. https://doi.org/10.1016/j.psep.2020.07.025

Chang, R. (1992). Compact hybrid particulate collector. US Patent. 5158580.

Chang, Y., Jia, P., Shi, L., Xiang, X. (2018). Corona discharging and particle collection of bipolar transverse plate ESP. J. Electrost. 96, 104-110. https://doi.org/10.1016/j.elstat.2018.10.004

Chang, Y., Jia, P., Xiang, X., Shi, L., Jiang, X. (2019). Investigation of the performance of filtrationcharged particles in a reversed electric field. Aerosol Air Qual Res. 19, 2879-2887. https://doi.org/10.4209/aaqr.2019.06.0283

Chen, H., Wang, T., Luo, Z., Zhou, D., Lu, M., He, M., Fang, M., Cen, K. (2017). Agglomeration kernel of bipolar charged particles in the presence of external acoustic and electric fields. Aerosol Air Qual. Res. 17, 857-866. https://doi.org/10.4209/aaqr.2016.09.0378

Deng, H., He, Z., Xu, Y., Ma, J., Liu, J., Guo, R. (2010). An investigation on two-phase mixture discharges: the effects of macroparticle sizes. J. Phys. D: Appl. Phys. 43, 255203. https://doi.org/10.1088/0022-3727/43/25/255203

Feng, B., Long, Z., Yu, T. (2016). Filtration characteristics of fibrous filter following an electrostatic precipitator. J. Electrost. 83, 52-62. https://doi.org/10.1016/j.elstat.2016.07.009

Feng, Z., Long, Z., Cao, S., Adamiak, K. (2018). Characterization of electrohydrodynamic (EHD) flow in electrostatic precitators (ESP) by numerical simulation and quantitative vortex analysis. J. Electrost. 91, 70-80. https://doi.org/10.1016/j.elstat.2017.12.008

He, M., Luo, Z., Lu, M., Liu, S., Fang, M. (2019). Effects of acoustic and pulse corona discharge coupling field on agglomeration and removal of coal-fired fine particles. Aerosol Air Qual. Res. 19, 2585-2596. https://doi.org/10.4209/aaqr.2018.08.0306

Hu, B., Yi, Y., Liang, C., Yuan, Z., Szczepan, R., Yang, L. (2018). Experimental study on particles agglomeration by chemical and turbulent agglomeration before electrostatic precipitators. Powder Technol. 335, 186-194. https://doi.org/10.1016/j.powtec.2018.04.016 
IEEE-DEIS-EHD Technical Committee (2003). Recommended international standard for dimensionless parameters used in electrohydrodynamics. IEEE Trans. Dielectr. Electr. Insul. 10, 3-6. https://doi.org/10.1109/TDEI.2003.1176545

Jaworek, A., Krupa, A., Czech, T. (2007). Modern electrostatic devices and methods for exhaust gas cleaning: A brief review. J. Electrost. 65, 133-155. https://doi.org/10.1016/j.elstat.2006.0 7.012

Jaworek, A., Marchewicz, A., Sobczyk, A.T., Krupa, A., Czech, T. (2018). Two-stage electrostatic precipitators for the reduction of $\mathrm{PM}_{2.5}$ particle emission. Prog. Energy Combust. Sci. 67, 206233. https://doi.org/10.1016/j.pecs.2018.03.003

Jaworek, A., Sobczyk, A.T., Krupa, A., Marchewicz, A., Czech, T., Śliwiński, L. (2019). Hybrid electrostatic filtration systems for fly ash particles emission control. A review. Sep. Purif. Technol. 213, 283-302. https://doi.org/10.1016/j.seppur.2018.12.011

Krupa, A., Podliński, J., Mizeraczyk, J., Jaworek, A. (2019). Velocity field of EHD flow during back corona discharge in electrostatic precipitator. Powder Technol. 344, 475-486. https://doi.org/ 10.1016/j.powtec.2018.12.006

Liu, J., Li, X. (2020). A computational investigation of particle acoustic agglomeration in a resonance tube. Powder Technol. 374, 82-94. https://doi.org/10.1016/j.powtec.2020.07.042

Miller, S.J. (1999). Advanced hybrid particulate collector and method of operation. US Patent. 678580.

Ni, Z., Luo, K., Gao, Y., Gao, X., Fan, J., Cen, K. (2018). Potential air quality improvements from ultralow emissions at coal-fired power plants in China. Aerosol Air Qual Res. 18, 1944-1951. https://doi.org/10.4209/aaqr.2018.02.0070

Noh, K.C., Park, J.H., Jung, Y.K., Yi, S., Hwang, J. (2011). Characteristics of submicron-sized aerosol filtration and pressure drop of an electret filter installed in an air diffuser in a residential apartment unit. Aerosol Air Qual. Res. 11, 80-89. https://doi.org/10.4209/aaqr.2010.11.0095

Robert, B., Nallathambi, G. (2020). A concise review on electrospun nanofibres/nanonets for filtration of gaseous and solid constituents $\left(\mathrm{PM}_{2.5}\right)$ from polluted air. Colloid Interface Sci. Commun. 37, 100275. https://doi.org/10.1016/j.colcom.2020.100275

Sobczyk, A., Marchewicz, A., Krupa, A., Jaworek, A., Czech, T., Śliwiński, Ł., Kluk, D., Ottaw, A., Charchalis, A. (2017). Enhancement of collection efficiency for fly ash particles $\left(\mathrm{PM}_{2.5}\right)$ by unipolar agglomerator in two-stage electrostatic precipitator. Sep. Purif. Technol. 187, 91-101. https://doi.org/10.1016/j.seppur.2017.06.039

Thonglek, V., Kiatsiriroat, T. (2014). Agglomeration of sub-micron particles by a non-thermal plasma electrostatic precipitator. J. Electrost. 71, 33-38. https://doi.org/10.1016/j.elstat.2013. 11.006

Tu, G., Song, Q., Yao, Q. (2018). Mechanism study of electrostatic precipitation in a compact hybrid particulate collector. Powder Technol. 328, 84-94. https://doi.org/10.1016/j.powtec.2 018.01.016

Wang, C., Tu, T., Syu, J., Kuo, C., Kuo, P., Jhong, Y., Lin, W. (2018). Experimental investigation of the filtration characteristics of charged porous fibers. Aerosol Air Qual Res. 18, 1470-1482. https://doi.org/10.4209/aaqr.2017.12.0582

Xiang, X., Jia, S., Chang, Y., Shi, L. (2020). Collection enhancement mechanism and test of side flow electrostatic precipitation. Aerosol Air Qual. Res. 20, 844-851. https://doi.org/10.4209/a aqr.2019.09.0454 